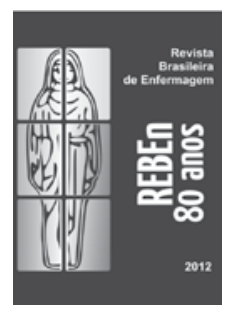

\title{
A pesquisa e os dilemas éticos do trabalho da Enfermagem
}

\author{
The research and the ethical dilemmas of Nursing work \\ La investigación y los dilemas éticos del trabajo de Enfermería
}

\author{
Raimunda Medeiros Germano' \\ 'Universidade Federal do Rio Grande do Norte, Centro de Ciências da Saúde, \\ Departamento de Enfermagem. Natal-RN, Brasil.
}

Submissão: 24-07-2013 Aprovação: 24-07-2013

\begin{abstract}
RESUMO
Trata o presente artigo de uma reflexão acerca da pesquisa e dos dilemas éticos do trabalho da enfermagem, tendo como principal objetivo fornecer subsídios para ajudar a pensar o cuidar, no cotidiano profissional, no campo do ensino, da pesquisa e, particularmente, da assistência. Recorremos a autores que tratam a respeito da ética, do trabalho e da condição humana, buscando a articulação entre esses conhecimentos e o fazer da Enfermagem, em seu cotidiano. Concluímos que diante da realidade da saúde, em meio a tantas adversidades com as quais nos deparamos, no dia-a-dia da prática profissional, seja no ensino, na pesquisa ou na assistência de Enfermagem, o pensar e agir com ética é uma condição estruturante, que enobrece e humaniza a profissão dando sentido às ações de seus profissionais.
\end{abstract}

Descritores: Ética; Enfermagem; Pesquisa.

ABSTRACT
This paper is a reflection on research and the ethical dilemmas of nursing work, with the primary objective of providing subsidies to help thinking about care, according to professional practice in the field of education, research, and particularly of assistance. We rely on authors who deal about ethics, labor and human condition, finding a link between this knowledge and nursing's doing in its daily practice. We conclude that given the reality of health, amid so many adversities with which we are faced in day-to-day practice, whether in teaching, research or nursing care, to think and to act ethically is a structuring condition, which humanizes and ennobles the profession giving meaning to the actions of its professionals.

Key words: Ethics; Nursing; Research.

\section{RESUMEN}

El presente artículo es una reflexión sobre la investigación y los dilemas éticos del trabajo de Enfermería, con el objetivo primordial de ofrecer subsidios para ayudar a pensar la atención, de acuerdo con la práctica profesional en el campo de la educación, la investigación, y en particular la asistencia. Recurrimos a autores que se ocupan de la ética, el trabajo y la condición humana, en la búsqueda de una relación entre este conocimiento y el quehacer de Enfermería en su vida diaria. Se concluye que, dada la realidad de salud, en medio de tantas adversidades con las que nos enfrentamos en la práctica diaria, ya sea en la docencia, la investigación o la atención de enfermería, pensar y actuar de manera ética es una condición estructurante, que humaniza y dignifica la profesión y que da sentido a las acciones de sus profesionales.

Palabras clave: Ética; Enfermería; Investigaciones.

\section{AUTOR CORRESPONDENTE Raimunda Medeiros Germano E-mail: rgermano@natal.digi.com.br}


A ética (...) continua problemática, ou seja, cria problema, o que nos obriga a pensar. Kostas Axelos

O autor da epígrafe que abre este artigo nos convida ao exercício cotidiano do pensar, particularmente, importante, quando queremos nos referir aos dilemas éticos que envolvem o trabalho da enfermagem.

Nesse sentido, abordaremos três dimensões significativas do fazer da Enfermagem: o ensino, a pesquisa e a assistência, conduzindo-os por uma reflexão ética. Para nós, a ética manifesta-se de maneira imperativa, como exigência moral, como um suporte estruturante de nossa própria sobrevivência, no trabalho e na vida.

Edgar Morin ${ }^{(1)}$ refere em seus estudos sobre ética que esse imperativo origina-se numa fonte interior ao indivíduo, que o sente no espírito como a injunção de um dever. E, ao mesmo tempo, provém de uma fonte externa, como a cultura, as crenças, as normas de uma comunidade. Cada um vive para si e para o outro em uma relação dialógica ao mesmo tempo, de forma complementar e antagônica. Portanto, ser sujeito é associar egoísmo e altruísmo. O autor assinala ser importante reconhecer nessa visão o aspecto vital do egocentrismo e a potencialidade fundamental do desenvolvimento do altruísmo.

É preciso reconhecer dentro desse contexto que todo olhar sobre a ética deve levar em consideração que a sua exigência é vivida subjetivamente. O universalismo ético tem um componente racional e um componente místico justificado pela herança da ascendência religiosa que marcou o pensamento ético através dos tempos. A ética não propõe a soberania da razão. Ela é frágil. Permanece incerta e inacabada; nunca está pronta; deve incessantemente regenerar-se.

Pensar os dilemas éticos do trabalho da Enfermagem significa enfrentar situações embaraçosas, qualquer que seja o campo de atuação profissional. A verdade é que o dilema nos coloca diante da dificuldade de escolher a solução ideal, diante de um raciocínio que parte de premissas contraditórias e mutuamente excludentes, em relação a uma determinada situação, ambas ingratas ou mesmo contrárias ao nosso sentir. Daí a importância de construirmos uma cultura ética no cotidiano do exercício profissional para não nos perdermos pelo viés do utilitarismo. Neste, decidem aqueles que têm o poder de decisão, têm autonomia sobre outros que vivem à margem, terminando por ser penalizados. Na sociedade em que vivemos, com profunda desigualdade social, cresce e se fortalece um cenário desumano, do descuido e do abandono. E, assim, a ética do cuidar assume uma importância cada vez maior diante das fragilidades da vida.

Pensando o ensino da ética / bioética, enfrentamos nosso primeiro dilema. No nosso entender, esse ensino tem uma transversalidade em toda a formação do enfermeiro e dos demais profissionais da Enfermagem; ou seja, todos os docentes transmitem uma ética, qualquer que seja seu campo de atuação, e, por vezes, esquecem ou mesmo banalizam esse compromisso. Nos cursos da área da saúde e, particularmente, na Enfermagem, o ensino de ética / bioética tem sido destacado como uma prioridade? Faz parte das disciplinas ditas estruturantes do currículo? Há um compromisso por parte do corpo docente, em seu conjunto, acerca dos princípios éticos que devem direcionar a prática de seus profissionais, qualquer que seja o espaço de atuação?

$\mathrm{E}$, ainda, continuamos com outras indagações, igualmente importantes face à direção ética da formação: $O$ conteúdo dos cursos/disciplinas de ética/bioética ultrapassa as questões meramente deontológicas da profissão? Da ética codificada? Do conhecimento técnico e científico? Ou caminha no sentido da bioética, buscando compreender o equilíbrio dos conflitos atuais e futuros entre os indivíduos e a natureza, englobando situações persistentes e emergentes que afligem a humanidade? Discute a melhoria das condições de vida, relacionando-as ao exercício da cidadania, e dos direitos humanos? Aponta para uma ética da compreensão, da complexidade, da tolerância, do reconhecimento, da solidariedade e, ainda, como nos adverte Habermas, da ação comunicativa?

As publicações acerca do tema confirmam que o ensino de ética com essa abordagem não vem sendo priorizado, ao contrário, ocupa um lugar secundário no conjunto das disciplinas dos cursos de graduação e pós-graduação, com ênfase, sobretudo, nos aspectos deontológicos. E assim, para os estudantes, ser ético significa, quando muito, apenas respeitar o código de sua profissão. Porém, mesmo pensando nos bons sentimentos contidos nos códigos de ética, os alunos se deparam com a contradição entre o discurso ético e a intervenção prática dos profissionais, no cotidiano dos serviços de saúde. É comum identificar-se a discriminação do cliente/usuário, em função de sua origem social, de forma banalizada, como sendo algo natural.

No exercício cotidiano dos profissionais de saúde, são inúmeras as arbitrariedades registradas a cada novo dia, mesmo em se tratando de instituições que se destinam ao ensino e à pesquisa, campo de aprendizagem, portanto, de estudantes dos diferentes cursos. Daí a importância da parceria entre ensino e serviço, dentro de um pacto ético, envolvendo docentes e profissionais de saúde, com vistas a melhor direcionar e enformar a ação discente, no processo de aprendizagem. Essa experiência é marcante, podendo tornar-se edificante quando o fazer técnico e o comportamento ético se misturam e constituem uma unidade, como ações inseparáveis.

No entanto, essa dicotomia se faz presente quer nas salas de aula, quer nos serviços de saúde, cujos aspectos técnicos são comumente priorizados, sem que se estabeleça, na maioria das vezes, qualquer relação com as dimensões humanas, sociais e, portanto, éticas. É comum a notificação da existência de despreocupação ou mesmo banalização, por parte dos profissionais, com o sofrimento, a dor, a condição humana. Quando, ao contrário, a ética preconiza a resistência à crueldade do mundo e à barbárie. Ela nos remete para a tolerância, a compaixão, a mansidão e a misericórdia. É pensar a própria realização da vida humana.

Ainda a propósito da formação como um todo, há uma marcante tendência a compartimentalização do saber e, em consequência, do ser a quem esse saber se destina. Em conformidade com Edgar Morin, “a hiperespecialização impede 
tanto a percepção do global (que ela fragmenta em parcelas), quanto do essencial (que ela dissolve") $)^{(2)}$. E ainda acrescenta o autor: "o recorte das disciplinas impossibilita apreender 'o que está tecido junto', ou seja, segundo o sentido original do termo, o complexo"(2).

Por outro lado, torna-se importante assinalar que, diante do reconhecimento de uma prática pedagógica pautada em uma metodologia fragmentada, característica de nossas disciplinas acadêmicas, há um movimento interno que aponta para uma renovação. Essa tendência em torno da discussão de novos projetos pedagógicos, dos diferentes cursos, abre o debate entre estudantes e professores, dentro de uma visão crítica da realidade de saúde e do próprio ensino. Em consequência, possibilita outro fazer pedagógico em consonância com as demandas sociais e as políticas governamentais de inclusão social.

Nessa perspectiva, o ensino de ética / bioética, diferentemente de outros conhecimentos ministrados, não deve acontecer como algo apenas pontual, e sim, integrar o currículo de forma transversal. Essa reflexão deve ser parte integrante do cotidiano de docentes, discentes e demais profissionais que conformam o universo do mundo acadêmico. E ainda: o ensino deve ter um caráter transdisciplinar para melhor apreender, em toda a sua complexidade, os diferentes desafios ligados aos avanços das ciências da vida.

Acerca da pesquisa, como parte integrante do trabalho da enfermagem, esta guarda estreita relação com o ensino, principalmente com o crescimento da pós-graduação; são novos horizontes que se abrem para o desenvolvimento da profissão, vislumbrando a melhoria da atenção de enfermagem em todos os níveis de complexidade. Assim concebendo, muitas são as questões de cunho ético a ser lembradas: Qual a direção e objetivo de nossas pesquisas? Há uma preocupação com a realidade a ser pesquisada? Há um retorno para essa realidade? Os participantes das pesquisas são respeitados em seus direitos? Elas estão contribuindo para tornar a prática cotidiana mais humana, valorizando a vida? Nas pesquisas que envolvem seres humanos, seus pesquisadores vêm observando, devidamente, as normas do Conselho Nacional de Saúde, a esse respeito? Encontra-se em vigor, atualmente, a Resolução CNS 466/2012, em substituição à Resolução 196/96 do mesmo Conselho. Há uma discussão acerca dessas resoluções entre pesquisadores, estudantes e profissionais? Essas são algumas indagações, entre tantas outras, que poderão e devem ser feitas.

Na mesma direção, ainda no campo da pesquisa, muitos outros problemas éticos precisam ser considerados, quando a pauta de discussão envolve a formação de novos profissionais. É preocupante observar como a competição e o produtivismo no meio acadêmico têm concorrido para a banalização da produção científica, constituindo um verdadeiro simulacro do saber. São reproduções de textos publicados via internet, sem qualquer participação do autor, como algo natural e aceitável. Pesquisadores e estudantes correm o risco de perder o senso e o compromisso ético em relação à pesquisa, mas igualmente, à prática cotidiana de cada um e à própria vida. Importa, sobretudo, registrar o quanto e onde produzem, sem que se estabeleça qualquer criticidade, a respeito do que foi produzido.

Reportando-nos a terceira área, a da assistência, não significa apenas mais uma dimensão do trabalho da enfermagem. Ela representa o espaço por excelência da prática profissional, realizando-se em todos os níveis de complexidade. É o lugar da expressão do cuidado, em toda sua plenitude. De acordo

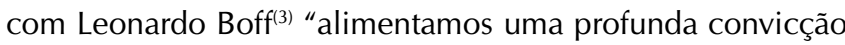
de que o cuidado, pelo fato de ser essencial, não pode ser suprimido nem descartado". É importante reconhecer que esse cuidado envolve não apenas a saúde, mas, igualmente, as outras dimensões da vida e, na enfermagem, ele se materializa, em todas as suas formas, no espaço da assistência.

É o mesmo autor que nos convida a pensar e exercer o cuidado, quando nos adverte, acerca do descuido e descaso pelos milhões de excluídos do processo de produção, do descuido e descaso pela coisa pública, pela dimensão espiritual do ser humano, descuido e abandono dos sonhos de generosidade, de sociabilidade, descuido e descaso pelas crianças, pelo destino dos pobres marginalizados da humanidade, descaso pelo próprio planeta, entre outras fragilidades no cuidar da vida ${ }^{(3)}$.

Na Enfermagem, o cuidar representa sua essência, embora outros profissionais, igualmente, cuidem. No entanto, é importante refletir qual o sentido que conferimos a nossa atividade laboral. Sabemos que o trabalho não é um fim em si mesmo, e sim a vida, como nos lembra Comte-Sponville ${ }^{(4)}$. Mas como um meio, como uma necessidade de realização do ser humano, dá sentido à vida de quem cuida e do ser cuidado. Portanto, é fundamental a consciência e o envolvimento de quem o executa, a busca de interação entre o cuidador e aquele que recebe o cuidado.

Em qualquer profissão, o fazer profissional, desprovido de sentido leva quem o pratica, ao sofrimento e à infelicidade. $\mathrm{O}$ sentido das coisas "não está apenas na realidade objetiva, está na história e na meta perseguida. (...) O sentido se constrói em nós com o que está antes de nós e depois de nós, com a história e a imaginação, a origem e a descendência"(5).

Por isso mesmo, ao refletir sobre o lugar que ocupa o cuidado na assistência de Enfermagem, torna-se oportuno recorrer ao campo da comunicação, assunto que se faz presente em todas as publicações dos autores que se dedicam ao tema cuidado. Entre tantas outras fontes, de cunho eminentemente teórico, que vêm contribuindo para os estudos de enfermagem nessa área, insere-se a ação comunicativa ou o agir comunicativo de Jürgen Habermas ${ }^{(6)}$.

De acordo com esse autor a ação comunicativa permite uma relação crítica com os três mundos com os quais nos confrontamos: mundo dos objetos, mundo social e mundo subjetivo. A linguagem assume, nesta ação, um papel central como meio regulador do comportamento mútuo ${ }^{(6)}$.

Conforme ainda o mesmo autor,

o agir comunicativo refere-se à interação de pelo menos dois sujeitos capazes de falar e agir que estabeleçam uma relação interpessoal (seja com meios verbais ou extraverbais). Os atores buscam um entendimento sobre a situação 
da ação para, de maneira concordante, coordenar seus planos de ação e, com isso, suas ações ${ }^{(6)}$.

Nessa perspectiva, os dilemas éticos deveriam ter soluções em ações comunicativas que busquem o consenso. $\mathrm{O}$ que tiver sido consensualmente acordado deve ser respeitado. Isto evitaria a automatização e a tecnificação das práticas cotidianas. $E$, nesse contexto, importa ainda referir que essa ação comunicativa é determinada, igualmente, pelos diferentes sistemas (econômico, social e político) que invadem o mundo da vida e da saúde.

No cotidiano dos serviços de saúde dificilmente podemos falar de ação comunicativa, propriamente, vez que o cliente/ usuário, sujeito da ação, raramente é convidado a participar da argumentação e da escolha de seu tratamento; ficando a critério dos profissionais decidirem sobre seu destino.

A comunicação com o cliente/usuário não tem se evidenciado como uma preocupação de primeira ordem, pela grande maioria de profissionais, dentre os quais se incluem os de enfermagem. Encanta, sobremaneira, o aparato tecnológico que aos poucos e de forma mais intensa, na atualidade, vem penetrando no mundo da saúde e no campo dos diagnósticos e tratamentos, particularmente, quando nos referimos aos centros de terapia intensiva. É muito comum, e as pesquisas na área confirmam, a solidão referida pelos clientes que vivenciaram a experiência de internamento nas terapias intensivas. A atenção dos profissionais parece concentrar-se, sobretudo, nas máquinas e exames sofisticados. Em tempo, nos adverte Mia Couto, escritor moçambicano, em uma crítica ao mundo moderno, ao qual nos estamos referindo - "Só um mundo novo nós queremos: o que tenha tudo de novo e nada de mundo".

Pensamos ser esse um momento oportuno para o exercício de reflexão, sobre o trabalho da enfermagem, por acreditarmos na possibilidade de um fazer mais humano, a partir de uma consciência crítica acerca da própria banalização, que por vezes ocorre, diante da dor do outro. Como assinala Edgar Morin ${ }^{(1)}$ o mal é o desastre, o horror da condição humana. Mas, o pior da crueldade e o melhor da bondade do mundo estão no ser humano. O combate essencial da ética é a dupla resistência à crueldade do mundo e à crueldade humana.

Portanto, encerramos essa reflexão com a esperança de que, diante das adversidades que envolvem o campo da saúde e da vida profissional, tenhamos condição de trilharmos o caminho da ética.

\section{REFERÊNCIAS}

1. Morin E. O método 6: ética. 4. ed. Porto Alegre: Sulina; 2011.

2. Morin E. Os sete saberes necessários à educação do futuro. São Paulo: Cortez; 2000.

3. Boff L. Saber cuidar. Ética do humano - compaixão pela terra. Petrópolis: Editora Vozes; 1999.

4. Comte-Sponville A. A vida humana. São Paulo: WMF
Martins Fontes; 2007.

5. Cyrulnik B. Falar de amor à beira do abismo. São Paulo: Martins Fontes; 2006.

6. Habermas J. Teoria do agir comunicativo-1. Racionalidade da ação e racionalização social. São Paulo: WMF Martins Fontes; 2012. 